\title{
MAPA DE FONTES EXTERNAS E INOVAÇÃO NO SETOR TÊXTIL SOROCABANO: ABORDAGEM COM AS ORGANIZAÇÕES DO SETOR DE FIAÇÃO E CONFECÇÃO
}

\author{
Statement of sources and innovation in the \\ external Sorocabano sector textil: Approach to the \\ organization of wire and garment sector
}

Envio 28.09.09 / Aceite 28.11.09

\author{
Manuel Antonio Munguía Payés ${ }^{1}$ \\ Rodrigo Diogo Teixeira ${ }^{2}$
}

\section{Resumo}

Este estudo objetiva pesquisar o uso de informações e conhecimentos de fontes externas para inovar, à luz do enfoque neo-schumpeteriano, tendo a base empírica restrita ao município de Sorocaba, SP. Foram realizadas entrevistas e aplicados questionários a uma amostra não-aleatória, constituída de 22 empresas industriais do setor têxtil. Para a análise dos dados, foi utilizada a estatística descritiva e a matriz de postos de correlação de Spearman. Concluiu-se que quanto maior a utilização de fontes externas de conhecimentos tecnológicos, maior a capacitação para inovar e vice-versa. Essa relação se apresentou forte entre as ramificações do setor têxtil: confecções e fiação. Nas empresas de confecções, as principais fontes de informações e conhecimentos tecnológicos externas empregadas na capacitação para inovar foram: clientes e/ou consumidores finais; fornecedores das máquinas, equipamentos, materiais, componentes e/ou softwares; concorrentes. Nas empresas de fiação, as principais fontes externas utilizadas foram: fornecedores das máquinas, equipamentos, materiais, componentes e/ou softwares; clientes e/ou consumidores finais; concorrentes. Os resultados de Spearman mostraram-

\footnotetext{
${ }^{1}$ Graduado em Economia pela Pontifícia Universidade Católica de Campinas (1978), mestre em Desenvolvimento, Agricultura e Sociedade pela Universidade Federal Rural do Rio de Janeiro (1980) e doutor em Ciência Econômica pela Universidade Estadual de Campinas (1990). Atualmente é professor titular da Universidade de Sorocaba. Tem experiência na área de Economia, com ênfase em Organização Industrial e Estudos Industriais, atuando principalmente com inovação e cooperação interindustrial. E-mail: manuel.payes@prof.uniso.br

${ }^{2}$ Bolsista da Fundação de Amparo à Pesquisa do Estado de São Paulo. E-mail: rodrigodediogo@gmail.com
} 
se muito significantes para ambas as organizações dos dois setores analisados, corroborando com a conclusão supracitada, apontando a importância do uso de fontes externas na capacidade inovativa, para inovações incrementais no setor têxtil na cidade de Sorocaba.

Palavras-chave: Inovação; Fontes Externas de Conhecimentos Tecnológicos; Setor Têxtil; Capacitação para Inovar.

\begin{abstract}
Interested in studying the relationship between the use of information and knowledge from external sources for innovation in the light of neo-Schumpeterian approach. Our empirical basis was restricted to the city of Sorocaba, SP. Were interviewed and a questionnaire to a non-random sample consisted of 22 industrial companies in the textile sector. For data analysis, we used descriptive statistics and the array of posts correlation. It follows that the greater the use of external sources of technological knowledge, the greater the capacity to innovate and vice versa. This relationship is presented strong among the branches of the textile sector: spinning and clothing. In business clothing the main sources of information and technological know-how used in external training to innovate were clients and / or end users, suppliers of machinery, equipment, materials, components and / or software; competitors. In spinning companies the main external sources were used: suppliers of machinery, equipment, materials, components and / or software, customers and / or final consumers, competitors. The results of Spearman were very significant for both organizations in the two sectors analyzed, corroborating the above conclusion, indicating the importance of using external sources innovative capacity for incremental innovations in the textile sector in the city of Sorocaba.
\end{abstract}

Keywords: Innovation; External Sources of Technological Knowledge; Textile Sector; Capacity to Innovate.

\title{
1 Introdução
}

A inovação é um fenômeno da maior importância nos estudos sobre organização industrial, porque, por meio dela, empresas e regiões tornam-se competitivas e viabilizam maiores taxas de crescimento econômico e de desenvolvimento social. Focando as organizações industriais, alguns especialistas costumam associar a capacitação para inovar à maior eficiência técnica dos processos produtivos adotados. A comparação de indicadores técnicos, do tipo insumo-produto, produtividade dos fatores, entre outros, com as best-practices verificadas na indústria, fornece um ranking e aponta as organizações mais eficientes. A análise por envoltória, desenvolvida por Charnes, Cooper e Rhodes (1978) é freqüentemente utilizada para o estudo da eficiência técnica.

A tese schumpeteriana sustenta que a busca (search) de inovações permite às organizações diferenciar-se de seus concorrentes, ganhar competitividade e apropriar-se de lucros extraordinários, ainda que temporários. Na visão neo-schumpeteriano ou evolucionista, a capacidade inovativa está associada com o desenvolvimento do aprendizado tecnológico. Aprende-se através da atividade de P\&D, isto é, quando as organizações realizam esforço tecnológico próprio e também absorvendo informações e conhecimentos externos à organização. No Brasil, recentes estudos empíricos que utilizaram como fonte principal de informações os microdados da Pesquisa Industrial de Inovação Tecnológica (PINTEC), elaborada pelo IBGE 
(2006), apresentaram resultados consistentes com a teoria (GONÇALVES, LEMOS e DE NEGRI, 2005; DE NEGRI, 2006).

O setor têxtil sorocabano, segundo os dados da RAIS do MTE, empregava $8 \%$ do estoque de trabalhadores da indústria do município em março de 2007; são 236 indústrias, o que representa $13 \%$ do total das indústrias instaladas no parque industrial de Sorocaba, SP. Cabe observar que o município de Sorocaba apresenta um parque industrial com significativa presença de empresas transnacionais, diversificado e representativo no estado de São Paulo, com poucas indústrias de porte grande no setor têxtil e muitas indústrias de porte médio e pequeno dentre as quais: fiação, confecções, malharias, tecelagem.

\begin{abstract}
As pequenas empresas concentram-se principalmente no segmento de vestuários, podendo estabelecer relacionamentos com firmas maiores principalmente através de serviços complementares de facção. No segmento têxtil, as pequenas firmas interagem com empresas de médio e grande porte através do fornecimento de produtos e serviços complementares (como o tingimento) sem maiores complexidades tecnológicas. O processo de imitação de produtos locais, nacionais ou estrangeiros é uma prática bastante comum entre estas firmas (CAMPOS et al., 2002, p.12).
\end{abstract}

Interessa, aqui, estudar a relação entre o uso de informações e conhecimentos de fontes externas e a capacitação para inovar. A base empírica deste estudo restringiu-se ao setor têxtil do município de Sorocaba, SP. Este município apresenta um parque industrial com significativa presença de empresas transnacionais, diversificado e representativo no Estado. Segundo a Fundação SEADE (2005), em 1993, o município de Sorocaba ocupou a décima quarta posição no ranking de municípios paulistas, segundo o valor adicionado fiscal da indústria, subindo para a décima segunda posição em 2001, último ano com a informação disponível. De acordo com o IBGE, em 2002, em termos de valor adicionado, a indústria radicada em Sorocaba ocupava a 40a posição no Brasil e a 12 $2^{a}$ no Estado de São Paulo. Conforme a Secretaria de Comércio Exterior (SECEX), Sorocaba ocupou, no Estado, a 11a posição no ranking de exportação em 2004.

O artigo divide-se em quatro seções além desta introdução. Na segunda, explicita-se a metodologia empregada. Na terceira, é desenvolvida o referencial conceitual que serviu de base para o desenvolvimento do estudo empírico. Na quarta, são apresentados os resultados da pesquisa. Na última seção, são apresentadas as considerações finais.

\title{
2 Material e método
}

A pesquisa se pautou em uma amostra de empresas retirada do "Cadastro de Estabelecimentos Empregadores", do Ministério do Trabalho e Emprego (sistema RAIS/CAGED). Foram selecionadas 55 empresas têxteis deste cadastro (grupos 172, 173, 181 do CNAE95), com 30 ou mais empregados em março de 2008, sendo que, respectivamente, 22 empresas colaboraram, sendo 16 empresas do ramo confecções e seis do ramo fiação. Dessa forma, para efeito de análise estatística dos dados, será considerado que foi realizada uma pesquisa de acordo com uma amostra não-aleatória de 22 empresas colaboradoras.

Foram entrevistados seis gerentes industriais, 16 proprietários, por um período aproximado de 50 a 60 minutos. O questionário aplicado aproveitou questões da Pesquisa de Inovação Tecnológica (PINTEC), do IBGE (2006). Na mensuração das respostas, utilizaram-se 
os seguintes pesos: não relevante, peso 0 ; importância baixa, peso 1 ; importância média, peso 2; e importância alta, peso 3.

Para efeito de análise estatística dos dados, foi utilizada a estatística descritiva e a Matriz de correlação de postos de Spearman, para verificar a associação entre o uso das fontes externas e a capacitação para inovar dessas organizações do setor têxtil.

\section{Referencial teórico}

No enfoque neo-schumpeteriano ou evolucionista, a utilização de fontes de conhecimentos tecnológicos relaciona-se com inovações, isto é, com o comportamento inovativo assumido pelas organizações na concorrência capitalista. A inovação de processos, produtos e organizacional é conseguida através do aprendizado. "O aprendizado é um processo pelo qual a repetição e a experimentação permitem que as tarefas sejam mais bem e mais rapidamente desempenhadas e que novas oportunidades de produção sejam identificadas" (TEECE, 2005, p. 154). O aprendizado, entendido como cumulativo e coletivo (no âmbito da organização), permite criar novos conhecimentos, competências e rotinas; portanto, permite gerar capacitação para inovar. Fontes internas e externas alimentam o processo de aprendizagem:

\footnotetext{
No caso das fontes internas, a formação de habilidades dentro da firma, juntamente com uma combinação dos resultados dos processos formais de aprendizagem (learning by doing, learning by using e learning by interacting), permite a acumulação de conhecimento por meio de suas próprias experiências de design, desenvolvimento de produtos e mercado. No que se refere às fontes externas, o elemento central são as diversas formas de interação entre os agentes (DE CAMPOS e DE PAULA, 2006, p. 43).
}

O trabalho de Cohen e Levintahl (1989) associa o processo de aprendizado tecnológico à ampliação do estoque de conhecimentos retidos pela organização e depende tanto das capacitações prévias quanto do acesso às fontes externas de informações e conhecimentos tecnológicos. Para esses autores, a ampliação do conhecimento e das capacitações tecnológicas das organizações expressa-se na seguinte equação:

$$
\begin{aligned}
& Z i=M i+Y i\left(€ \sum M j+T\right), \\
& \text { sendo: } \\
& -Z i=\text { ampliação do estoque de conhecimentos da organização i; } \\
& -M i=\text { esforço tecnológico da organização; } \\
& -Y i=\text { capacidade de absorção do conhecimento externo; } \\
& -€=\text { spillovers; } \\
& -M j=\text { esforço tecnológico de organizações intra-indústria (concorrentes); e } \\
& -T=\text { montante de conhecimento extra-indústria. }
\end{aligned}
$$

Para Cohen e Levintahl (1989), o esforço tecnológico (Mi) da organização i no tempo t é função basicamente do investimento em pesquisa e desenvolvimento (P\&D). O esforço em P\&D tem duplo papel. De um lado, é precondição para aprimorar a eficiência operacional e gerar conhecimento, competências e rotinas que dão origem à inovação. De outro, potencializa a capacidade de absorção ou de aprendizado (Yi), isto é, a capacidade de identificar, assimilar e explorar a informação e o conhecimento externo à organização. 
Um dos principais fatores que credenciam as empresas a assimilar conhecimentos de fontes externas está relacionado ao seu próprio esforço tecnológico. A razão para isso é a característica cumulativa do conhecimento científico. Em outras palavras, quanto maior é o conhecimento prévio adquirido pela firma, por meio dos seus investimentos em pesquisa em alguma área específica, maior é sua capacidade de absorver conhecimento naquela área em um período posterior. Além disso, conhecimentos prévios capacitam a firma a entender e avaliar melhor a importância dos novos desenvolvimentos tecnológicos. Não é por acaso que muitos estudos utilizam o esforço tecnológico das firmas como uma boa aproximação para sua capacidade de absorção (DE NEGRI, 2006, p. 10).

Os spillovers (€) representam os "transbordamentos" ou "vazamentos" de informações e conhecimentos relacionados com o esforço tecnológico de organizações rivais (Mj), mas seu aproveitamento depende da maior ou menor capacidade de absorção da organização; enquanto T expressa o montante de informações e conhecimentos extra-indústria.

Todavia, embora a realização de P\&D seja a principal maneira de resumir o esforço tecnológico, há outros meios, notadamente nos países em desenvolvimento, em que a inovação é, em grande parte, do tipo incremental, como a qualificação dos funcionários (GONÇALVES; LEMOS; DE NEGRI, 2005; DE NEGRI, 2006). Antonelli (1996) inclui também no esforço tecnológico o investimento em aprendizado dos trabalhadores (L). Aqui é preciso focar a capacitação e o treinamento orientados ao desenvolvimento e à introdução de inovações ou aprimoramentos.

De acordo com Manual de Oslo (2004, p. 34),

\begin{abstract}
Muitos dos conhecimentos tecnológicos exibem as características de um bem público já que os custos de torná-los disponíveis a muitos usuários são baixos em comparação com os custos de seu desenvolvimento e que, uma vez disseminados, não se pode negar novos acessos aos usuários. Esta característica é a fonte de dois dos problemas principais enfrentados pelos inovadores privados. O primeiro é o transbordamento dos benefícios da inovação (externalidades positivas), o fato de que o retorno social da inovação é geralmente mais alto do que o retorno privado (clientes e concorrentes se beneficiam das inovações de uma empresa). O segundo problema é, na verdade, outro aspecto do primeiro - o conhecimento não pode ser apropriado. Em tal caso, a empresa não pode capturar todos os benefícios gerados por sua inovação, o que reduz o incentivo para investimento em atividades inovadoras. Assim, onde o conhecimento tecnológico tiver características de bem público, haverá uma falha nas forças de mercado (falha de mercado) que, não fora isto, poderia motivar as empresas a inovar.
\end{abstract}

Analisando o caso brasileiro, percebe-se que existe ainda muito a ser feito, com a finalidade de aumentar a capacidade inovativa e a capacidade produtiva, de modo a ampliar incentivos à socialização do conhecimento para que, cada vez mais, as empresas busquem por inovar e trazer um desenvolvimento tanto tecnológico quanto social, melhorando a qualidade de vida das pessoas, seu nível de renda e bem-estar, sendo fundamental para o processo de desenvolvimento socioeconômico.

A capacidade de absorção (Yi) da firma i no tempo t é cumulativa e depende do próprio esforço tecnológico (Mi) e também da complexidade e adequação das informações e conhecimentos externos às necessidades e preocupações da firma. A capacidade de absorção difere do tipo de aprendizado learning-by-doing. "Neste, a firma torna-se mais experiente e mais eficiente em executar algo que já faz. Naquele, o conhecimento externo adquirido a 
capacita a fazer algo completamente diferente" (GONÇALVES, LEMOS e DE NEGRI, 2005, p. 2). Além disso, a capacidade de absorção difere entre as organizações, ou seja, as organizações possuem diferentes graus de capacidade de absorção. Isto significa que, quanto maior a capacidade de absorção, mais apta apresenta-se uma organização para aproveitar informações e conhecimentos tecnológicos externos. Daí que "não há razão para supor que as firmas em uma indústria se beneficiem igualmente do conhecimento tecnológico de suas rivais" (ALMEIDA, 2004, p. 8). DE NEGRI (2006), por outro lado, reconhece que o conceito de capacidade de absorção é difícil de mensurar, pois é um tanto subjetivo. A autora, na sua investigação empírica, aponta a utilização das fontes externas de conhecimento tecnológico como imprescindível no aumento da capacidade de absorção das firmas, na busca por inovações. Quadros et al. (apud GONÇALVES, LEMOS e DE NEGRI, 2005, p. 2) analisaram os dados da Pesquisa da Atividade Econômica Paulista (PAEP), da Fundação SEADE-SP, com informações de mais de 10.000 empresas estabelecidas no estado de São Paulo para o período 1994-1996 e concluíram que, ao invés do departamento de P\&D da própria empresa, "clientes, competidores e departamentos de outras organizações foram as principais fontes de informação para inovar".

A busca pela maximização da utilização de conhecimentos tecnológicos de fontes internas e externas reflete-se na introdução de inovações e, neste contexto, o verbo inovar passa a ter a conotação de ser sempre atual, com o ambiente externo à firma, há também que se considerar que a ampliação do estoque de conhecimentos internos é o promotor da decodificação das informações e conhecimentos externos.

A maior parte das atividades ligadas à inovação nos países em desenvolvimento refere-se à difusão, adaptação e melhoria de tecnologias já existentes, mais do que à geração de novas tecnologias (Nelson, 1993). Freqüentemente, estas atividades são realizadas junto com funções de rotina, como o controle de qualidade, a engenharia de manutenção e a engenharia de manufatura, ou ainda no âmbito de pequenos grupos de engenharia de produto e processo, ao invés de laboratórios de P\&D formalmente organizados.

Portanto, nestes países, é ainda mais importante medir os variados aspectos da inovação tecnológica, que vão além da atividade de P\&D. Neste contexto, a difusão de uma metodologia para pesquisas de inovação, com base no Manual de Oslo, tem se revelado útil e oportuna para que os países emergentes aumentem seu conhecimento sobre as decisões e a capacidade de inovação das empresas. Isto decorre do fato de as pesquisas de inovação focarem as distintas dimensões da inovação tecnológica (QUADROS et al., 1999, p. 53).

A globalização traz em si a integração dos sistemas produtivos mundiais, obrigando as organizações produtivas dos países em desenvolvimento a reverem suas políticas industriais pela ótica da inovação; mesmo assim, lacunas ainda persistem em relação a uma maior compreensão das reais implicações das organizações de apoio ao sistema de inovação, para o desenvolvimento tecnológico dos vários setores industriais.

Todas as formas de conhecimentos possuem um aspecto tácito significativo, altamente complementar' as informações codificadas, que as torna incorporadas a pessoas ou organizações e um tanto infensas a transmissão. Com efeito, esta é uma das razões fundamentais pelas quais o emparelhamento tecnológico dos países em desenvolvimento continua sendo uma tarefa desafiadora mesmo numa época de globalização e de livre fluxo das informações (CIMOLI et al., 2007, p. 8). 
Para Nonaka et al. (2008 apud BALESTRIN e VERSCHOORE, 2008, p. 130-131) os conhecimentos tecnológicos integralizados via aprendizado de fontes externas, agregados aos conhecimentos internos de cada firma, agregam valor às firmas. Estes conhecimentos são, em geral, tácitos, por estarem fortemente relacionados a ações, rotinas, procedimentos, o que torna o processo de aprendizado dinâmico e essencialmente humanista por estarem ligados às ações humanas.

Demonstra-se que (1) organizações e agentes que cooperam introduzem maior num erode inovações do que os que não cooperam e que (2) 0 grau de inovação aumenta com a variedade de parceiros comunicando-se e cooperando em rede (PATRUCCO apud ALBAGLI et al. 2004, p.11).

O fluxo de conhecimentos de fontes externas, de acordo com Fallgatter (2006, p.155156), pode se originar tanto de empresas do mesmo setor, fontes empresariais, como de fontes de fomento à ciência, universidades ou institutos de pesquisa, por exemplo. A utilização dessas fontes amplia o estoque de conhecimento industrial, aumentando a competitividade organizacional.

\section{Resultados}

As inovações adotadas pelas empresas do setor têxtil (aqui representadas por firmas de confecções e fiação) foram do tipo incremental (nova para empresa, mas existente no mercado nacional; nova no mercado nacional, mas existente no mercado mundial; nova para a empresa, mas já existente em outra empresa do grupo e, ainda, um aprimoramento substancial de um produto ou processo já existente na empresa planta local. As 22 empresas integrantes da amostra do setor têxtil são de capital nacional. Inexiste o departamento de pesquisa e desenvolvimento formal dentro dessas firmas. O que há são realizações conjuntas de vários departamentos internos realizando as atividades de um departamento de P\&D.

\section{Setor têxtil}

\section{Setor de confecções}

O quadro I relaciona a média de trabalhadores, origem do capital e o tipo de inovação realizada no período 2005-2007, nas 16 empresas de confecções analisadas neste estudo.

\begin{tabular}{|ccc|}
\hline \hline \multicolumn{3}{|c|}{ Caracterização do ramo de Confecções } \\
\hline $\begin{array}{c}\text { Média do número de } \\
\text { funcionários empregados em } \\
\text { março de 2008 }\end{array}$ & Origem do capital & Tipo de inovação \\
\hline 63 & $100 \%$ nacional & $100 \%$ incremental \\
\hline \hline
\end{tabular}

Quadro I - Caracterização do ramo de confecção.

No estudo de Sugahara e Jannuzzi (2005, p. 47), as fontes externas, relacionadas na PINTEC (IBGE, 2005), foram classificadas didaticamente da seguinte forma: (a) fontes externas ligadas às atividades de mercado: fornecedores, clientes e/ou consumidores, concorrentes e outras empresas do grupo; (b) fontes externas de caráter profissional: feiras e exposições conferências, encontros e publicações especializadas e redes de informação informatizadas; e (c) fontes externas especializadas e institucionais: as atividades para aquisição de licenças, patentes 
e know-how, realizadas por universidades, institutos de pesquisa, empresas de consultoria ou consultores independentes. Nesta pesquisa, foram consideradas as seguintes fontes externas: outra empresa do grupo; fornecedores das máquinas, equipamentos, materiais, componentes e/ou softwares; clientes e/ou consumidores; concorrentes; empresas de consultoria e/ou consultores independentes; universidades, instituição profissional e/ou assistência técnica; instituições de testes, ensaios e/ou certificações; aquisição de licenças, patentes e/ou know-how; conferências, encontros e/ou publicações especializadas, redes de informação informatizadas, feiras e exposições.

Nas empresas de confecções, as principais fontes externas de informações e conhecimentos tecnológicos responsáveis pela capacitação para inovar foram: clientes e/ou consumidores finais; fornecedores das máquinas, equipamentos, materiais, componentes e/ ou softwares; concorrentes; aquisição de licenças, patentes e/ou know-how (ver Tabela 1). Este resultado está em conformidade com o estudo de Sugahara e Jannuzzi (2005). De acordo com esses autores, há variações do uso da fonte externa em relação à especificidade de cada setor industrial e a sua capacitação para inovar, pois, segundo eles, a importância das fontes são decrescentes à medida que determinado setor da indústria tem taxa de inovação menor, como o caso do setor têxtil. Sobre a utilização das fontes externas pelas indústrias inovadoras, os autores descrevem:

Quanto às informações sobre licenças e patentes, observa-se que a relevância do uso desta fonte é predominante nas classes de indústrias mais inovadoras, como era de se esperar. É importante mencionar que as informações técnicas dos inventos patenteados podem estar disponíveis antes da inserção do produto no mercado. Além disso, como observou França (1997, p. 252), o conjunto de documentos sobre patentes de determinado setor permite evidenciar a evolução do estado-da-arte dos inventos neste setor direcionando novos caminhos de P\&D. Além das feiras e exposições, as conferências e publicações especializadas e redes de informações informatizadas são fontes de informação expressivas para as indústrias com alta inovação. É interessante observar que o grau de importância destas fontes decresce à medida que diminui a classe da taxa de inovação (SUGAHARA e JANNUZZI, 2005 p. 53).

Rev. Adm. UFSM, Santa Maria, v. 2, n. 3, p. 433-447, set./dez. 2009 
Tabela 1 - Média de utilização das fontes externas importantes na aquisição da capacitação para inovar no ramo de confecções sorocabano entre 2005-2007

\begin{tabular}{|c|c|c|c|c|c|c|c|c|c|c|c|c|}
\hline \multicolumn{13}{|c|}{ FONTES EXTERNAS: SETOR CONFECÇÕES } \\
\hline Empresa & Clie & F. & Cr. & $\begin{array}{l}\mathbf{A q} \\
\mathbf{L c}\end{array}$ & $\begin{array}{l}\text { O. } \\
\text { e. }\end{array}$ & Univ & $\begin{array}{c}\text { I. t. } \\
\text { c. }\end{array}$ & $\begin{array}{l}\text { Cf. } \\
\text { enc. }\end{array}$ & $\begin{array}{l}\text { E. } \\
\text { Cons }\end{array}$ & $\begin{array}{l}\text { R. } \\
\text { Info }\end{array}$ & $\begin{array}{c}\text { Fe. } \\
\text { Exp. }\end{array}$ & $\begin{array}{c}\text { Total } \\
\text { score } \\
\text { fontes } \\
\text { externas } \\
\end{array}$ \\
\hline e.1 & 3 & 0 & 2 & 0 & 0 & 2 & 0 & 0 & 0 & 0 & 0 & 7 \\
\hline e.2 2 & 2 & 3 & 1 & 1 & 2 & 2 & 2 & 1 & 2 & 0 & 0 & 16 \\
\hline e.3 & 2 & 3 & 1 & 2 & 2 & 1 & 2 & 1 & 1 & 0 & 0 & 15 \\
\hline e. 4 & 3 & 2 & 2 & 2 & 1 & 0 & 2 & 0 & 0 & 0 & 0 & 12 \\
\hline e.5 & 3 & 1 & 2 & 0 & 0 & 3 & 0 & 0 & 0 & 0 & 0 & 9 \\
\hline e.6 & 3 & 3 & 3 & 2 & 2 & 1 & 0 & 0 & 1 & 0 & 0 & 15 \\
\hline e. 7 & 3 & 3 & 2 & 2 & 2 & 1 & 2 & 3 & 3 & 0 & 0 & 21 \\
\hline e.8 & 3 & 2 & 1 & 1 & 3 & 2 & 2 & 1 & 0 & 0 & 0 & 15 \\
\hline e.9 & 2 & 2 & 3 & 0 & 0 & 0 & 0 & 2 & 0 & 0 & 0 & 9 \\
\hline e.10 & 3 & 3 & 2 & 2 & 2 & 0 & 2 & 0 & 0 & 0 & 0 & 14 \\
\hline e.11 & 3 & 3 & 3 & 2 & 0 & 2 & 2 & 2 & 0 & 0 & 0 & 17 \\
\hline e. 12 & 2 & 1 & 2 & 0 & 0 & 0 & 0 & 0 & 0 & 0 & 0 & 5 \\
\hline e.13 & 3 & 2 & 2 & 3 & 0 & 3 & 3 & 2 & 0 & 0 & 0 & 18 \\
\hline e.14 & 3 & 3 & 0 & 3 & 3 & 0 & 0 & 2 & 0 & 0 & 0 & 14 \\
\hline e. 15 & 2 & 2 & 3 & 1 & 3 & 1 & 2 & 0 & 0 & 0 & 0 & 14 \\
\hline e.16 & 2 & 2 & 3 & 2 & 0 & 2 & 0 & 2 & 0 & 0 & 0 & 13 \\
\hline Total & 42 & 35 & 32 & 23 & 20 & 20 & 19 & 16 & 7 & 0 & 0 & 214 \\
\hline $\begin{array}{l}\text { Méd. } \\
\text { aritm. }\end{array}$ & 2,63 & 2,19 & 2 & 1,44 & 1,25 & 1,25 & 1,19 & 1,0 & 0,44 & 0 & $\mathbf{0}$ & 13,40 \\
\hline
\end{tabular}

Obs. A importância de cada fonte foi avaliada pelos dirigentes das organizações como: a) não relevante (peso 0); b) baixa importância (peso 1); c) média importância (peso 2); e d) alta importância (peso 4). Significado das abreviações: clie $=$ clientes; F. $=$ fornecedores de máquinas, equipamento, software; $\mathrm{Cr}=$ concorrentes; Aq. Lç. = aquisição de licenças, patentes e know-how; O. e. = outra empresa do grupo; Univ = universidades, institutos de pesquisa; I. t. c. = Institutos de testes e certificações; Cf. enc. = conferências encontros, publicações especializadas; E. cons = empresas de consultoria e/ou consultores independentes; R. Info. = redes de informação informatizadas; Fe. Expo. = feiras e exposições. 
Ao desagregar-se a inovação, vê-se a predominância de inovações incrementais e verifica-se que a maior parte das inovações das organizações do setor de confecção foram semi-radicais, aquelas que são novas para o mercado nacional, porém já existentes no mercado mundial, como se vê na tabela 2.

Tabela 2 - Classificação da inovação adotada por tipo

\begin{tabular}{cccccc}
\hline \multicolumn{7}{c}{ INOVAÇÃO POR CLASSES } \\
\hline Empresa & AP.SUB & NE.MRN & NE.MRM & NE.NMRM & Total score INO \\
\hline e.1 & 1 & 0 & 0 & 0 & 1 \\
e.2 & 1 & 2 & 0 & 0 & 3 \\
e.3 & 1 & 2 & 0 & 0 & 3 \\
e.4 & 0 & 0 & 3 & 0 & 3 \\
e.5 & 1 & 0 & 0 & 0 & 1 \\
e.6 & 1 & 2 & 0 & 0 & 3 \\
e.7 & 1 & 2 & 3 & 0 & 6 \\
e.8 & 0 & 0 & 3 & 0 & 3 \\
e.9 & 1 & 0 & 0 & 0 & 1 \\
e.10 & 0 & 0 & 3 & 0 & 3 \\
e.11 & 0 & 0 & 3 & 0 & 3 \\
e.12 & 1 & 0 & 0 & 0 & 1 \\
e.13 & 0 & 2 & 0 & 0 & 2 \\
e.14 & 1 & 0 & 0 & 0 & 1 \\
e.15 & 0 & 2 & 0 & 0 & 2 \\
e.16 & 0 & 0 & 3 & 0 & 3 \\
\hline Total & $\mathbf{9}$ & $\mathbf{1 2}$ & $\mathbf{1 8}$ & $\mathbf{0}$ & $\mathbf{3 9}$ \\
\hline Méd. aritm. & $\mathbf{0 , 5 6}$ & $\mathbf{0 , 7 5}$ & $\mathbf{1 , 1 2}$ & $\mathbf{0}$ & $\mathbf{2 , 4 4}$ \\
\hline
\end{tabular}

Obs. O peso de cada tipo de inovação foi avaliado pelos dirigentes das organizações como: a) AP. SUB (peso 1); b) NE.MRN (peso 2); c) NE.MRM (peso 3); e d) NE.NMRM (peso 4). Abreviações: AP. SUB = aprimoramento substancial de um produto ou processo já existente; NE.MRN = nova para a empresa mais já existente no mercado nacional; NE.MRM = nova para a empresa mais já existente no mercado mundial; NE.NMRM = nova para a empresa e nova para o mercado mundial, este tipo de inovação é a que autores da literatura chamam de radical ou revolucionária.

O resultado da matriz de correlação de postos de Spearman para o ramo de confecção que relacionou o uso de fontes externas com as inovações adotadas (relacionando tabelas 1 e 1 apontando que as empresas que mais empregaram fontes externas também foram as que mais se capacitaram para inovar em produto e em processo. Segundo os resultados de Spearman, com um pvalue $<0,05$, o resultado se mostrou muito significativo, comprovando que, para as empresas deste grupo industrial, o aprendizado tecnológico e a capacitação para inovar estão ligados ao grau de utilização das fontes externas. Veja o resultado apresentado na tabela 3. 
Tabela 3 - Resultado Spearman para confecções

$$
\begin{gathered}
\text { Coeficiente de Spearman }(\mathrm{rs})=0.6826 \\
\mathrm{t}=3.4950 \\
(\mathrm{p})=0.0036 \\
\text { Número de pares }=16 \\
\text { Resultado significativo. }
\end{gathered}
$$

\section{Setor de fiação}

O quadro 2 caracteriza as seis empresas de fiação, tomando como variáveis (1) a média de trabalhadores, (2) a origem do capital e (3) o tipo da inovação realizada no período 2005-2007.

\begin{tabular}{|ccc|}
\hline \hline \multicolumn{3}{|c|}{ Caracterização do ramo de Fiação } \\
\hline $\begin{array}{c}\text { Média do número de } \\
\text { funcionários empregados em } \\
\text { março de 2008 }\end{array}$ & Origem do capital & Tipo de inovação \\
\hline 99 & $84 \%$ nacional e $16 \%$ misto & $100 \%$ incremental \\
\hline \hline
\end{tabular}

Quadro 2 - Caracterização do ramo de fiação

Nas empresas de fiação, as principais fontes externas de informações e conhecimentos tecnológicos responsáveis pela capacitação para inovar na média de utilização foram: fornecedores das máquinas, equipamentos, materiais, componentes e/ou softwares; clientes e/ou consumidores finais; concorrentes; aquisição de licenças, patentes e/ou know-how. A tabela 4 aponta, em ordem decrescente, as fontes externas mais importantes para aquisição da capacitação para inovar, das organizações industriais do setor de fiação.

Tabela 4 - Média de utilização das fontes externas importantes na aquisição da capacitação para inovar no ramo de fiação sorocabano entre 2005-2007

\section{FONTES EXTERNAS: SETOR FIAÇÃO}

\begin{tabular}{l|l|l|l|l|l|l|l|l|l|l|l|l}
\hline Empresa & F. & Clie & Cr. & $\begin{array}{l}\text { Aq } \\
\text { Lç }\end{array}$ & $\begin{array}{l}\text { I. t. } \\
\text { c. }\end{array}$ & $\begin{array}{l}\text { Cf. } \\
\text { enc. }\end{array}$ & Univ & $\begin{array}{l}\text { O. } \\
\text { e. }\end{array}$ & $\begin{array}{l}\text { E. } \\
\text { Cons }\end{array}$ & $\begin{array}{l}\text { R. } \\
\text { Info }\end{array}$ & $\begin{array}{l}\text { Fe. } \\
\text { Exp. }\end{array}$ & $\begin{array}{l}\text { Total } \\
\text { score }\end{array}$ \\
\hline e.1 & 3 & 1 & 3 & 3 & 2 & 2 & 0 & 1 & 0 & 0 & 0 & 15 \\
\hline e. & 2 & 2 & 1 & 2 & 2 & 2 & 0 & 0 & 0 & 0 & 0 & 11 \\
\hline e. 3 & 3 & 3 & 2 & 0 & 1 & 1 & 0 & 0 & 0 & 0 & 0 & 10 \\
\hline e.4 & 2 & 3 & 3 & 2 & 0 & 0 & 3 & 1 & 0 & 0 & 0 & 14 \\
\hline e.5 & 3 & 3 & 3 & 3 & 3 & 2 & 2 & 3 & 0 & 0 & 0 & 22 \\
\hline e.6 & 3 & 3 & 2 & 3 & 2 & 1 & 2 & 0 & 0 & 0 & 0 & 16 \\
\hline Total & $\mathbf{1 6}$ & $\mathbf{1 5}$ & $\mathbf{1 4}$ & $\mathbf{1 3}$ & $\mathbf{1 0}$ & $\mathbf{8}$ & $\mathbf{7}$ & $\mathbf{5}$ & $\mathbf{0}$ & $\mathbf{0}$ & $\mathbf{0}$ & $\mathbf{8 8}$ \\
\hline $\begin{array}{l}\text { Méd. } \\
\text { aritm. }\end{array}$ & $\mathbf{2 , 6 7}$ & $\mathbf{2 , 5 0}$ & $\mathbf{2 , 3 3}$ & $\mathbf{2 , 1 7}$ & $\mathbf{1 , 6 7}$ & $\mathbf{1 , 3 3}$ & $\mathbf{1 , 1 7}$ & $\mathbf{0 , 8 3}$ & - & - & - & $\mathbf{1 4 , 6 7}$ \\
\hline
\end{tabular}

Obs. A importância de cada fonte foi avaliada pelos dirigentes das organizações como: a) não relevante (peso 0); b) baixa importância (peso 1); c) média importância (peso 2); e d) 
alta importância (peso 4). Significado das abreviações: clie = clientes; F. = fornecedores de máquinas, equipamento, software; $\mathrm{Cr}=$ concorrentes; Aq. Lç. = aquisição de licenças, patentes e know-how; O. e. = outra empresa do grupo; Univ = universidades, institutos de pesquisa; I. t. c. = Institutos de testes e certificações; Cf. enc. = conferências encontros, publicações especializadas; E. cons = empresas de consultoria e/ou consultores independentes; R. Info. = redes de informação informatizadas; Fe. Expo. = feiras e exposições.

Ao desagregar-se a inovação, vê-se a predominância de inovações incrementais e um maior uso de fontes externas na adoção de capacitação para inovar. Pode-se notar que as inovações da classe nova para a empresa, mas já existente no mercado mundial, ou seja, aquela semi-radical, são mais utilizadas nas organizações do setor de fiação do que nas organizações de confecção, haja vista que, no setor de fiação, há também uma maior média de utilização de fontes externas em todas as classes (média de uso de fontes externas setor confecções total = 13,40; média de uso de fontes externas setor fiação total = 14,67).

A tabela 5 mostra os diferentes tipos de inovações introduzidas pelas empresas do setor de fiação no período entre 2005 e 2007. Da mesma forma que no setor de confecções, os dirigentes das organizações classificaram as inovações como: (a) aprimoramento substancial de um produto ou processo já existente -AP. SUB (peso 1); (b) nova para a empresa, mais já existente no mercado nacional -NE.MRN (peso 2); (c) nova para a empresa, mas já existente no mercado mundial -NE.MRM (peso 3); e d) nova para a empresa e nova para o mercado mundial -NE.NMRM (peso 4).

Tabela 5 - Inovação por classes

\begin{tabular}{cccccc}
\hline Empresa & AP.SUB & NE.MRN & NE.MRM & NE.NMRM & $\begin{array}{c}\text { Total } \\
\text { score }\end{array}$ \\
\hline e.1 & 0 & 0 & 3 & 0 & 3 \\
e.2 & 0 & 2 & 0 & 0 & 2 \\
e.3 & 1 & 0 & 0 & 0 & 1 \\
e.4 & 0 & 0 & 3 & 0 & 3 \\
e.5 & 0 & 0 & 3 & 0 & 3 \\
e.6 & 1 & 2 & 0 & 0 & 3 \\
\hline Total & $\mathbf{2}$ & $\mathbf{4}$ & $\mathbf{9}$ & $\mathbf{0}$ & $\mathbf{1 5}$ \\
\hline Méd. aritm. & $\mathbf{0 , 3}$ & $\mathbf{0 , 6}$ & $\mathbf{1 , 5}$ & $\mathbf{0}$ & $\mathbf{2 , 5}$ \\
\hline
\end{tabular}

Obs. O peso de cada tipo de inovação foi avaliado pelos dirigentes das organizações como: a) AP. SUB (atribuímos o peso 1); b) NE.MRN (peso 2); c) NE.MRM (peso 3); e d) NE.NMRM(peso 4). Abreviações: AP. SUB = aprimoramento substancial de um produto ou processo já existente; NE.MRN = nova para a empresa mais já existente no mercado nacional; NE.MRM = nova para a empresa mais já existente no mercado mundial; NE.NMRM = nova para a empresa e nova para o mercado mundial, este tipo de inovação é a que autores da literatura chamam de radical ou revolucionária.

O resultado da matriz de correlação de postos de Spearman (ver Tabela 6) para as empresas do ramo de fiação relacionou o uso de fontes externas a inovações destas organizações (relacionando as tabelas 4 e 5) mostra que a capacitação para inovar das organizações deste setor está amplamente relacionada com o uso das fontes de conhecimentos tecnológicos de 
agentes externos na esfera do mercado no qual estão inseridas. Com um pvalue $<0,05$, temse: as empresas desse ramo que mais empregaram fontes externas foram aquelas que mais se capacitaram para inovar entre 2005-2007. O resultado de Spearman que mostrou grande significância é apresentado na Tabela 6.

TABELA 6 - Resultado Spearman para fiação

\begin{tabular}{c}
\hline Coeficiente de Spearman $(\mathrm{rs})=0.8452$ \\
$\mathrm{t}=3.1623$ \\
$(\mathrm{p})=0.0341$ \\
Número de pares $=6$ \\
\hline Resultado Significativo
\end{tabular}

\section{Considerações finais}

Os resultados alcançados foram coerentes com o enfoque teórico adotado e mostrou que quanto maior a utilização de fontes externas de conhecimentos tecnológicos, maior a capacitação para inovar e vice-versa. É evidenciado que as empresas do setor têxtil mostraram um maior uso dos conhecimentos tecnológicos das fontes externas para inovar e todas as inovações são claramente identificadas com as do tipo incremental. $\mathrm{O}$ uso desse tipo de fonte se mostra forte no setor têxtil e parece estar relacionado com as inovações incrementais adotadas. Essa estratégia parece estar relacionada com a inovação incremental e como o montante de investimento requerido. Com efeito, a interação de fontes externas ligadas as atividades de mercado, como fornecedores, clientes e/ou consumidores, concorrentes, requer menos investimento do que a realização de P\&D dentro das organizações.

Nas empresas de confecções, as principais fontes de informações e conhecimentos tecnológicos externas foram: clientes e/ou consumidores, fornecedores e concorrentes. Nas empresas de fiação, as principais fontes externas utilizadas foram: fornecedores, clientes e concorrentes.

Cabe apontar que o emprego predominante de fontes externas vem capacitando as organizações para o desenvolvimento e adoção de inovações incrementais, isto é, para a imitação. Isto parece revelar que a adoção de inovações radicais exigiria um maior esforço tecnológico próprio. 


\section{Referências}

ALBAGLI, Sarita et al. Informação e conhecimento na inovação e no desenvolvimento local.Ci, Inf., Brasília, v. 33, n. 3, p.9-16, set./dez. 2004

ALMEIDA, Sergio. Um modelo evolucionário de busca tecnológica. In: ENCONTRO NACIONAL DE ECONOMIA, 32., 2004, João Pessoa, Paraíba. Anais... Brasília: ANPEC, 2004. Disponível em: <http://www.anpec.org.br/encontro_2004. htm>. Acesso em: 13 fev. 2007.

ANTONELLI, Cristiano. Localized knowledge percolation processes and information networks. Journal of Evolutionary Economics, v. 6, n 3, p.281-295, Sep. 1996.

BALESTRIN, Alsones; VERSCHOORE, Jorge.

Redes de cooperação empresarial: estratégias de gestão na nova economia. Porto Alegre: Bookman, 2008.

CAMPOS RAMOS, Renato; CÁRIO FERRAZ, Sílvio; NICOLAU ANTONIO; José; VARGAS, Geraldo. Aprendizagem por interação: pequenas empresas em sistemas produtivos e inovativos locais. UFRJ, Rio de Janeiro, 2002.

CIMOLI, Mario et al. Instituições e políticas moldando o desenvolvimento industrial: uma nota introdutória. Revista Brasileira de Inovação, Rio de Janeiro, v. 6, n. 1, p.55-85, jan./jun. 2007.

CASSIOLATO, J. Eduardo; CAMPOS, R. Ramos; STALLIVIERI, Fabio. Processos de aprendizagem e inovação em setores tradicionais: os arranjos produtivos locais de confecções no Brasil. In: ENCONTRO NACIONAL DE ECONOMIA, XXXIV, 2006, Salvador (Bahia). Anais. Brasília: ANPEC, 2006. Disponível em: <http://www. anpec.org.br/encontro_2006.htm > . Acessado em 13 fev. de 2007

CHARNES, A.; COOPER, W.; RHODES, E. Measuring the efficiency of decision-making units. European Journal of Operations
Research, n.3, p.429-444, 1978.DE WULF, K.; COHEN, W.M.; LEVINTHAL, D.A. Innovation and learning: the two faces of R\&D. Economic Journal, v.99, n. 397, p. 569-596, 1989.

DE CAMPOS, Antonio Carlos; DE PAULA, Nilson Maciel. Novas formas de organização industrial e o conceito de firma: uma abordagem neoschumpeteriana. Ensaios FEE, Porto Alegre, v. 27, n. 1, p. 31-56, maio 2006.

DE NEGRI, Fernanda de. Determinantes da inovação e da capacidade de absorção nas firmas Brasileiras: qual a influência do perfil da mão-de-obra? In: ENCONTRO NACIONAL DE ECONOMIA, 34., 2006, Salvador, Bahia. Anais... Brasília: ANPEC, 2006. Disponível em: < http:// www.anpec.org.br/encontro_2006.htm>. Acesso em: 13 fev. 2007.

IBGE. Pesquisa de inovação tecnológica

(PINTEC)-2005: instruções para o preenchimento do questionário. Rio de Janeiro: IBGE, 2006.

FALLGATTER, Micheline G. H. Indicadores a construção de um modelo de inovação organizacional: relações entre as estratégias das empresas do setor têxtil de Blumenau e as redes externas componentes do entorno da inovação. 2006. Tese (Doutorado em Economia) - Instituto de Economia, Universidade Federal de Santa Catarina, Florianópolis, 2006.

FUNDAÇÃO SISTEMA ESTADUAL DE ANÁLISE DE DADOS (SEADE). Produto Interno Bruto: PIB Municipal. São Paulo, 2005. Disponível em: $<$ http:// www.seade.gov.br/produtos $>$. Acesso em: 13 fev. 2007.

GONÇALVES, Eduardo; LEMOS, Mauro Borges; DE NEGRI, João Alberto. Determinantes do esforço inovador no brasil. In: ENCONTRO NACIONAL DE ECONOMIA, 33., 2005, Natal, Rio Grande do Norte. Anais... Brasília: ANPEC, 2005. Disponível em: <http://www.anpec.org. br/encontro_2005.htm >. Acesso em: 13 fev. 2007.

MANUAL DE OSLO. Proposta de diretrizes para coleta e interpretação de dados sobre inovação tecnológica. OCDE, 2004. 
QUADROS, Ruy; FURTADO, André;

BERNARDES, Roberto C.; FRANCO,

Eliane. Padrões de inovação tecnológica

na indústria paulista: comparação com os

países industrializados. Revista São Paulo em

Perspectiva, v.13, n. 1-2, p.53-66, 1999.

RELATÓRIO SETORIAL DA INDÚSTRIA TÊXTIL

BRASILEIRA. Brasil Têxtil 2008. São Paulo:

Instituto de Estudos e Marketing Industrial (IEMI),

v.8, n.8, p.1-152, ago.2008

SUGAHARA, Cibele Roberta; JANNUZZI,

Paulo de Martino. Estudo do uso de fontes de informação para inovação tecnológica na indústria brasileira. Ci. Inf., Brasília, v.34, n.1, p.45-56, jan./abr. 2005.

TEECE, David J. As aptidões das empresas e o desenvolvimento econômico. In: KIN, Linsu;

NELSON, Richard R. (Org.). Tecnologia,

aprendizado e inovação: as experiências

das economias de industrialização recente.

Campinas: Unicamp, 2005. p. 147-178. 